\title{
ANALISIS USAHATANI KANGKUNG (Ipomoea aquatica Forsk) DI DESA KAIMA KECAMATAN KAUDITAN KABUPATEN MINAHASA UTARA
}

\author{
Pedro R. P. Hutahaean \\ Mex L. Sondakh \\ Theodora M. Katiandagho
}

\begin{abstract}
This study aims to analyze how the income of water spinach farmers (Ipomoea aquatica Forsk). This research was conducted in Kaima Village, Kauditan District, North Minahasa Regency and lasted from April 2016 until October 2017. The research method used in this research is survey method by interview all farmers of kangkung. Data collection method in this research is to use primary data through prepared list of questions that are obtained through direct interviews with farmers and secondary data from related agencies such as Head of Village Office, Statistic and Agricultural Extension Offices. Sampling method is the determination of saturated samples means that all water spinach farmers are used as a sample much as 6 respondents. The concept of measurement of variables in this study is the production, land area, selling price, revenue, expenditure, and supporting variables. Analysis of data used is the data obtained are presented in table form and analyzed descriptively. The results showed that the income of kangkung farming in Kaima Village, Kecamatan.Kauditan was beneficial.
\end{abstract}

Keywords: analysis of kangkung farming business, Kaima Village, Kauditan Sub-district, North Minahasa Regency

\begin{abstract}
ABSTRAK
Penelitian ini bertujuan untuk menganalisis berapa pendapatan petani kangkung air (Ipomoea aquatica Forsk). Penelitian ini dilakukan di Desa Kaima, Kecamatan Kauditan, Kabupaten Minahasa Utara dan berlangsung selama bulan April 2016 sampai bulan Oktober 2017. Metode penelitian yang digunakan dalam penelitian ini adalah metode survei dengan cara mengunjungi petani kangkung. Metode pengumpulan data dalam penelitian ini adalah dengan menggunakan data primer melalui kuesioner yang telah disiapkan yang di peroleh melalui wawancara langsung dengan petani serta data sekunder dari instansi-instansi yang terkait seperti Kantor Hukum Tua, Badan Pusat Statistik dan Badan Penyuluh Pertanian Kabupaten Minahasa Utara . Metode pengambilan sampel yaitu penentuan sampel jenuh artinya semua petani kangkung dijadikan sebagai sampel sebanyak 6 responden. Konsep pengukuran variabel dalam penelitian ini adalah produksi, luas lahan, harga jual, penerimaan, pengeluaran, dan variabel penunjang. Analisis data yang digunakan adalah data yang diperoleh disajikan dalam bentuk table dan dianalisis secara deskriptif. Hasil penelitian menunjukan pendapatan usahatani kangkung di Desa Kaima, Kecamatan.Kauditan yaitu menguntungkan.
\end{abstract}

Kata kunci: analisis usahatani kangkung, Desa Kaima, Kecamatan Kauditan, Kabupaten Minahasa Utara 


\section{PENDAHULUAN}

\section{Latar Belakang}

Sektor pertanian merupakan sektor yang masih mendominasi perekonomian Minahasa Utara, dapat di lihat dari Pendapatan Domestik Regional Bruto (PDRB) sektor pertanian dalam 5 tahun terakhir. Sub sektor tanaman pangan memiliki peranan penting karena merupakan sumber pangan masyarakat, berbagai program swasembada pangan di lakukan untuk peningkatan produksi pangan terutama padi. Di Minahasa Utara ada 6 Kecamatan penghasil kangkung (Ipomoea aquatica Forsk) dari 10 kecamatan yang ada. Kecamatan Kauditan menduduki peringkat ke 4 daerah penghasil kangkung. Klein Charles, seorang ahli gizi menyebutkan bahwa manfaat sayuran terutama yang dibuat menjadi jus, dapat menghilangkan lemak didalam tubuh, menghilangkan kolestrol jahat, dan menurunkan tekanan darah tinggi. Banyak sekali jenis sayuran yang dapat kita pilih untuk dikonsumsi, baik untuk di masak, dimakan sebagai lalap, atau dibuat menjadi jus. Dibuat seperti apapun, kita masi tetap bisa merasakan manfaat sayuran bagi kesehatan kita. Kesadaran masyarakat tentang pentingnya sayuran bagi kesehatan beberapa tahun belakangan ini, masyarakat Indonesia semakin menyadari pentingnya gaya hidup sehat. Makin banyak orang yang rajin berolah raga untuk kebugaran dan mulai menghindari makanan tak sehat. Namun demikian masih banyak juga yang kurang menyadari pentingnya nutrisi yang baik melalui makanan dan minuman seperti buah dan sayuran segar. Bahkan bila dibandingkan dengan negara Asia Tenggara lainnya, konsumsi buah dan sayuran di Indonesia masih tergolong rendah. Berdasarkan survei yang dilakukan Badan Penelitian dan Pengembangan Kesehatan (Balitbangkes), konsumsi sayuran dan buah masyarakat Indonesia hanya 91 gram per hari, ini hanya sekitar setengah dari konsumsi masyarakat Thailand dan Filipina, atau seperlima dari konsumsi masyarakat Singapura yang sebesar 518 gram per hari. Hal berbeda yang terjadi di Desa Kaima Kecamatan Kauditan dimana beberapa petani padi justru beralih menjadi petani kangkung, karena budidaya kangkung relatif lebih sederhana dan mudah di lakukan di bandingkan dengan usaha tani padi, dan pendapat beberapa petani, perawatan sayur kangkung lebih mudah dibandingkan dengan bercocok tanam padi sawah, dan juga masa panennya lebih singkat dan memiliki harga yang lebih meyakinkan. Kangkung merupakan salah satu sayuran hijau yang permintaannya terus meningkat, seiring dengan kesadaran masyarakat untuk hidup sehat. Kangkung merupakan salah satu sayuran yang ada dalam makanan khas bubur manado (tinutuan), juga merupakan sayuran yang banyak di minati masyarakat untuk di konsumsi sehari- hari. Dan juga merupakan salah satu menu yang selalu ada di rumah-rumah makan yang ada di Minahasa Utara. Kangkung merupakan salah satu sayuran yang banyak disukai masyarakat di Sulut untuk di konsumsi sebagai makanan lalap, selain itu sayur kangkung juga menjadi bahan dasar pembuatan bubur manado atau tinutuan, dan juga sebagai sayuran yang banyak diminati seluruh lapisan masyarakat. Hampir disetiap rumah tangga yang ada di Wilayah Minahasa Utara mengkonsumsi sayur kangkung bahkan lebih sering dikonsumsi karna sayur kangkung bisa dikatakan sudah menjadi sayuran favorit bagi masyarakat sulut dan sekitarnya. Permintaan sayur kangkung ini ditanggapi oleh petani di Desa Kaima yang mulai mengalihkan usaha taninya dari padi sawah menjadi usaha tani kangkung. Sayur-sayuran merupakan salah satu jenis tanaman hortikultura yang dalam pembangunan ekonomi mempunyai prospek yang cerah di pasaran, seperti halnya tanaman kangkung yang semula hanya berkembang secara alami dan sederhana, tapi setelah berproduksi ternyata dapat menambah pendapatan keluarga petani. Sayur kangkung merupakan salah satu jenis sayuran yang mempunyai potensi untuk dikembangkan karena bernilai ekonomi tinggi. Peningkatan produksi kangkung mempunyai arti penting dalam menunjang persediaan pangan dan juga kangkung banyak disukai masyarakat karena merupakan sumber gizi yang murah harganya dan mudah didapat Rukmana (1994). Desa Kaima yang berada di Kecamatan Kauditan 
Kabupaten Minahasa Utara merupakan salah satu daerah potensial untuk mengembangkan sayur kangkung. Selain itu memiliki luas panen yang tertinggi diantara beberapa kecamatan dan urutan ke 4 (empat) dalam jumlah produksi tanaman kangkung, seperti yang terdapat dalam Tabel 1. Tabel 1 menunjukan bahwa Kecamatan Kauditan memiliki produksi kangkung kedua tertinggi di Minahasa Utara, dari 10 kecamatan yang ada di Kabupaten Minahasa Utara. Salah satu daerah penghasil kangkung di Kabupaten Minahasa Utara adalah Desa Kaima. Selain memproduksi kangkung, yang menarik dari petani kangkung di Desa Kaima ini, sebelumnya merupakan petani padi sawah. Pengalihan usahatani padi ke usahatani ini yang menjadi daya tarik utama sehingga penelitian ini dilakukan.

Tabel 1. Luas Panen dan Produksi Tanaman Sayuran Kangkung menurut Kecamatan di Kabupaten Minahasa Utara 2013-2014

\begin{tabular}{|c|c|c|c|}
\hline \multicolumn{4}{|c|}{ Kabupaten Minahasa Utara 2013-2014 } \\
\hline \multicolumn{2}{|c|}{ Kecamatan } & \multirow{2}{*}{$\begin{array}{l}\text { Luas Panen } \\
\begin{array}{r}\text { (Ha) } \\
\end{array} \\
\end{array}$} & \multirow{2}{*}{$\begin{array}{l}\begin{array}{l}\text { Produksi } \\
\text { (Ton) } \\
47,6\end{array}\end{array}$} \\
\hline 1. & Kema & & \\
\hline 2. & Kauditan & 53 & 43,0 \\
\hline 3. & Airmadidi & 2 & 1,4 \\
\hline 4. & Kalawat & 48 & 366,5 \\
\hline 5. & Dimembe & 28 & 44,9 \\
\hline & Talawaan & 0 & 0,0 \\
\hline & Likupang Selatan & 0 & 0,0 \\
\hline & Likupang Timur & 11 & 1,7 \\
\hline & Likupang Barat & 0 & 0,0 \\
\hline & Wori & 0 & 0,0 \\
\hline & & 150 & $\mathbf{5 0 5 , 1}$ \\
\hline & & 161 & 787,9 \\
\hline
\end{tabular}

Sumber: Dinas Pertanian, Peternakan, dan Perkebunan Kabupaten Minahasa Utara

\section{Rumusan Masalah}

Rumusan masalah dalam penelitian ini adalah Peralihan petani sawah keusaha tani kangkung di Desa Kaima Kecamatan Kauditan perlu di kaji dan dipertimbangkan dalam penelitian ini yaitu: Berapa pendapatan usaha tani sayur kangkung di Desa Kaima Kecamatan Kauditan?

\section{Tujuan Penelitian}

Penelitian ini bertujuan untuk menganalisis berapa pendapatan petani kangkung di Desa Kaima.

\section{Manfaat Penelitian}

Manfaat yang diperoleh dari penelitian ini diharapkan dapat memberi informasi dan bahan masukan untuk petani dalam mengelolah biaya usaha tani kangkung dapat dimanfaatkan semaksimal mungkin mengan memperhatikan biaya yang dikeluarkan agar bisa mendapatkan keuntungan yang semaksimal mungkin dan bisa menjadi informasi untuk peneliti selanjutnya.

\section{METODOLOGI PENELITIAN}

\section{Tempat dan Waktu Penelitian}

Penelitian ini dilakukan di Desa Kaima Kecamatan Kauditan Kabupaten Minahasa Utara dan berlangsung selama bulan April 2016 sampai bulan Oktober 2017, dari persiapan sampai dengan semua penyusunan laporan penelitian.

\section{Metode Penelitian}

Metode yang digunakan dalam penelitian ini adalah metode survei dengan cara mengunjungi petani kangkung yang ada di Desa Kaima Kecamatan Kauditan.

\section{Metode Pengumpulan Data}

Metode pengumpulan data dalam penelitian ini adalah dengan menggunakan data primer melalui kuisioner yang telah disiapkan yang di peroleh melalui wawancara langsung dengan petani serta data sekunder dari instansiinstansi yang terkait seperti Kantor Hukumtua, BPS dan Badan Penyuluh Pertanian.

\section{Metode Pengambilan Sampel}

Penelitian ini dilaksanakan di Desa Kaima Kecamatan Kauditan Minahasa Utara 
karena di desa ini terdapat petani yang mengelola usahatani kangkung pada lahan sawah. Penentuan sampel jenuh artinya semua petani kangkung dijadikan sebagai sampel sebanyak 6 (enam) responden.

\section{Konsep Pengukuran Variabel}

Adapun variabel-variabel yang diukur dalam penelitian ini adalah

1. Produksi, yaitu jumlah kangkung yang dihasilkan dalam jangka waktu satu bulan (Jumlah Per bal Kangkung)

2. Luas lahan, yaitu luas lahan yang diusahakan petani sawah (Ha)

3. Harga jual, yaitu harga yang berlaku di tingkat petani $(\mathrm{Rp} / \mathrm{bal})$

4. Penerimaan, yaitu perkalian antara total produksi dan harga komoditi

5. Pengeluaran, yaitu semua biaya yang dikeluarkan dari usahatani Kangkung (Rp), meliputi:

a. Biaya Tetap

1) Pajak Tanah, besarnya sesuai dengan luas dan daya guna lahan (Rp/tahun)

2) Penyusutan Peralatan, yaitu nilai penggunaan alat disebabkan oleh pemakaian alat selama proses produksi

$$
\begin{array}{cl}
\multicolumn{1}{c}{\boldsymbol{D}=\frac{\boldsymbol{H a w}-\boldsymbol{H a} \boldsymbol{k}}{\boldsymbol{W P}}} \\
\text { dimana D } & =\text { Penyusutan } \\
& \text { Haw = Nilai awal } \\
\text { Hak = Nilai akhir } \\
\text { WP = Waktu Pakai }
\end{array}
$$

b. Biaya variabel, yaitu biaya yang langsung mempengaruhi besarnya produksi yang dihasilkan seperti:

1) Pupuk, yaitu banyaknya pupuk yang digunakan oleh petani.

2) Pestisida, yaitu banyaknya pestisida yang digunakan petani dalam mengatasi hama penyakit.

3) Tenaga Kerja, yaitu biaya yang digunakan mulai dari pemeliharaan sampai dengan pasca panen yang terdri dari: Biaya pemeliharaan (penyiangan, pemupukan, pemberantasan hama), penen (pemetikan), pasca panen (pengepakan, pangangkutan).
6. Variabel penunjang adalah karakteristik Petani yang meliputi :

a. Umur petani

b. Tingkat pendidikan

c. Jumlah Anggota keluarga

d. Luas lahan yang dimiliki

\section{Analisis Data}

Data yang diperoleh disajikan dalam bentuk table dan dianalisis secara deskriptif dan untuk mengetahui besarnya pendapatan yang diperoleh petani kangkung sawah digunakan rumus:

$$
\mathrm{FI}=\mathrm{TR}-\mathrm{TC}
$$

Dimana: FI = Farm Income (Pendapatan Usaha Tani)

TR $=$ Total Receipts (Total Penerimaan)

$\mathrm{TC}=$ Total Expense $($ Total Biaya)

\section{HASIL DAN PEMBAHASAN}

\section{Deskripsi Wilayah Penelitian}

\section{Letak dan Luas Wilayah}

Desa Kaima adalah salah satu desa yang berada di Kecamatan Kauditan, yang terletak 3 (tiga) kilometer dengan waktu tempuh 10 (sepuluh) menit dari ibukota kecamatan. Desa Kaima memiliki ketinggian sekitar 300 meter dari permukaan laut, dengan suhu udara ratarata $21^{0} \mathrm{C}$ sampai $31^{\circ} \mathrm{C}$.

Adapun batas wilayah Desa Kaima adalah sebagai berikut:

Sebelah utara : Gunung Kelabat

Sebelah timur : Desa Treman Kecamatan Kauditan dan Perkebunan Waleo Kecamatan Kauditan

Sebelah selatan : Desa Waleo Kecamatan Kema dan Kinaleosan Kecamatan Kombi

Sebelah barat : Desa Karegesan dan Perkebunan Desa Kaasar Kecamatan Kauditan

Desa Kaima memiliki luas wilayah 886,6 hektar (ha), dimana lahan pertanian seluas 761,6 ha, lahan pemukiman 21 ha, dan penggunaan lainnya seluas 104 ha. Terdapat beberapa sungai yang melintasi Desa Kaima yaitu sungai 
Sawangen, Samido, Warinsouw, Waltang, dan sungai Kepangian. Jarak dari desa ke pusat pemerintahan provinsi yaitu 26 kilometer $(\mathrm{km})$, ke pusat pemerintahan kabupaten yaitu $7 \mathrm{~km}$, ke pusat pemerintahan kecamatan yaitu $3 \mathrm{~km}$, dan ke pelabuhan Bitung $19 \mathrm{~km}$, serta jarak ke bandara Sam Ratulangi yaitu 32 km.

\section{Penduduk}

Jumlah kepala keluarga (KK) yang berdomosili di Desa Kaima sebanyak 746 KK, yang terdiri penduduk laki-laki berjumlah 1.262 jiwa dan penduduk perempuan 1.204 jiwa, jumlah keseluruhan 2.466 jiwa. Mata pencaharian sebagian besar penduduk desa Kaima adalah petani sebanyak 54 persen $(\%)$. Komoditas pertanian yang mendominasi yaitu kelapa, cengkih, pala, padi sawah jagung, dan kangkung. Dalam upaya peningkatan pengelolaan sektor pertanian, perkebunan, dan perikanan darat, pemerintah Desa Kaima telah membentuk kelompokkelompok tani. Kelompok-kelompok tani tersebut tergabung dalam Gabungan Kelompok Tani (Gapoktan) Sekamiuman Desa Kaima. Gapoktan Sekamiuman terdiri dari 10 kelompok tani, yakni:

1. Kelompok tani Mandiri Kaima

2. Kelompok tani Permata Bunda Jaya

3. Kelompok tani Padembean Jaya

4. Kelompok budidaya Mina Sejahtera

5. Kelompok budidaya Talaga Mas

6. Kelompok tani Kelabat Indah

7. Kelompok tani Esa Genang

8. Kelompok tani Maesa-Esaan

9. Kelompok tani Kaima Jaya

10. Kelompok budidaya Ikan Jaya

Selain sebagai petani, mata pencarian penduduk Desa Kaima sebagai wiraswasta sebesar 17,7 persen (\%), 12,8 persen sebagai Aparatur Sipil Negara (ASN) dan $7 \%$ sebagai pedagang serta $2,4 \%$ sebagai pegawai swasta, secara rinci mata pencarian penduduk Desa Kaima dapat dilihat pada Tabel 2.
Tabel 2. Proporsi Penduduk Desa Kaima menurut

\begin{tabular}{rlr}
\multicolumn{2}{c}{ Mata Pencarian } & \multicolumn{1}{c}{ Mata } \\
No & \multicolumn{1}{c}{ Pencarian } & Persentasi (\%) \\
\hline 1 & Tani & 54,4 \\
2 & Aparatur Sipil & 12,8 \\
& Negara & \\
3 & TNI/POLRI & 0,4 \\
4 & Pegawai Swasta & 2,4 \\
5 & Wiraswasta & 17,7 \\
6 & Pedagang & 7,0 \\
7 & Tukang & 0,9 \\
8 & Lain-lain & 4,4 \\
\hline & Total & 100,0 \\
\hline
\end{tabular}

\section{Jumlah Anggota Keluarga Responden}

Tanggungan keluarga petani responden meliputi istri, anak, dan anggota keluarga lainnya yang bersama-sama dengan petani. Jumlah anggota keluarga petani responden dapat dilihat dari Tabel 3.

Tabel 3. Jumlah Anggota Keluarga Responden

\begin{tabular}{cccc}
\hline No & $\begin{array}{c}\text { Jumlah } \\
\text { Anggota } \\
\text { Keluarga }\end{array}$ & $\begin{array}{c}\text { Jumlah } \\
\text { Responden }\end{array}$ & Presentase \\
\hline 1 & 3 & 4 & 66,67 \\
2 & 2 & 1 & 16,67 \\
3 & 1 & 1 & 16,67 \\
\hline Jumlah & 15 & 6 & 100,00 \\
\hline
\end{tabular}

Pada Tabel 3 menunjukkan bahwa tanggungan keluarga petani responden sebagaian besar memiliki tanggungan 3 orang berjumlah 4 orang responden $(67,67 \%)$, jumlah tanggungan 2 orang berjumlah 1 responden $(16,67 \%)$, dan jumlah tanggungan 1 orang hanya 1 responden $(16,67 \%)$. Jumlah responden 6 orang dan jumlah tanggungan keseluruhan 15 orang.

\section{Status Kepemilikan dan Luas Lahan}

Status kepemilikan lahan yang digarap oleh petani responden di Desa Kaima menentukan besar kecilnya penerimaan dan biaya serta pendapatan yang akan diterima petani. 
Tabel 4. Status Kepemilikan Lahan Responden

\begin{tabular}{clrr}
\hline No & $\begin{array}{c}\text { Status } \\
\text { Kepemilikan }\end{array}$ & $\begin{array}{c}\text { Jumlah } \\
\text { Responden }\end{array}$ & $\begin{array}{c}\text { Persentase } \\
(\boldsymbol{\%})\end{array}$ \\
\hline 1 & Milik Sendiri & 1 & 16,67 \\
2 & Sewa & 5 & 83,33 \\
\hline & Total & 6 & 100,00 \\
\hline
\end{tabular}

Sumber : Data Olahan

Dari tabel 4 dapat dilihat status kepemilikan lahan petani responden, sebagian besar yaitu lahan sewa sebanyak 5 responden $(83,33 \%)$ dan 1 responden(16,67\%) yang lahannya milik sendiri. Luas dan keadaan lahan yang dimiliki petani responden bervariasi dari 0,06 ha sampai dengan 2 ha.

\begin{tabular}{|c|c|}
\hline Responden & Luas Lahan \\
\hline 1 & 2,00 \\
\hline 2 & 1,50 \\
\hline 3 & 1,00 \\
\hline 4 & 0,12 \\
\hline 5 & 0,06 \\
\hline 6 & 0,04 \\
\hline
\end{tabular}

Sumber : Data Olahan

Luas lahan sangat berpengaruh baik terhadap jumlah produksi maupun dalam penggunaan pupuk dan pemakaian air. Adapun luas lahan yang digunakan petani untuk usahatani kangkun sebagaimana yang terdapat dalam Tabel 5.

\section{Pengolahan Tanah dan Penanaman Kangkung}

Pekerjaan awal dalam usaha tani kangkung ini diawali dengan penyiapan lahan dan bibit kangkung yang dibeli atau diambil dari tanaman kangkung yang sudah ada pada lahan tersebut. Benih yang digunakan adalah benih kangkung darat yang bersertifikasi. Sedangkan untuk benih yang stek diperoleh dari tanaman kangkung air varietas lokal. Kedua tanaman ini digabung dalam satu area dan akhirnya terjadi persilangan antara kangkung darat dan kangkung lokal, dan jenis kangkung ini disebut kangkung "Manohara". Selanjutnya pembuatan petak untuk menanam bibit kangkung, dalam pembuatan petak ini termasuk juga pengolahan lahan dan pengurangan lumpur yang ada di petak. Dalam penyiapan lahan menggunakan dua sampai tiga orang pekerja tergantung dari luas petak yang akan ditanami kangkung, makin luas petak makin banyak tenaga kerja yang dibutuhkan. Tenaga kerja berasal dari dalam maupun luar keluarga. Setelah petak yang akan ditanami kangkung sudah siap, langkah berikutnya penanaman bibit kangkung yang telah disediakan sebelumnya. Setelah penanaman bibit pada petak yang disiapkan, selama satu minggu sesudah penanaman petak dibiarkan tanpa pengairan. Ketinggian air disesuaikan dengan umur tanaman kangkung dan tinggi tanaman kangkung, biasanya pada umur satu minggu sesudah tanam ketinggian air kurang lebih sepuluh centimeter $(10 \mathrm{~cm})$ dari permukaan lumpur. Selain pengairan, petani juga memberi pupuk guna merangsang pertumbuhan tanaman terutama pertumbuhan batang dan daun serta penyemprotan hama dan penyakit tanaman kangkung. Pupuk yang digunakan biasanya pupuk urea sedangkan hama yang biasanya menyerang adalah keong. Petani juga harus menunggu jangka waktu 4 sampai 7 minggu untuk masa panen pertama sayur kangkung, dan panen berikutnya memerlukan jangka waktu dua minggu untuk masa panen berikutnya dan seterusnya kangkung siap di panen.

\begin{tabular}{|c|c|c|c|c|c|c|}
\hline Responden & $\begin{array}{c}\text { Tenaga } \\
\text { kerja } \\
\text { (orang) }\end{array}$ & $\begin{array}{c}\text { Upah } \\
\text { Tenaga } \\
\text { Kerja/ } \\
\text { Hari } \\
\text { (Rp) }\end{array}$ & $\begin{array}{l}\text { Waktu } \\
\text { Kerja } \\
\text { (HOK) }\end{array}$ & $\begin{array}{l}\text { Total } \\
\text { Upah } \\
\text { (Rp) }\end{array}$ & $\begin{array}{c}\text { Sewa } \\
\text { Traktor } \\
(\mathbf{R p})\end{array}$ & $\begin{array}{l}\text { Total Biaya } \\
\text { Pembuatan } \\
\text { Petak (Rp) }\end{array}$ \\
\hline 1 & 3 & 100.000 & 3 & $\begin{array}{r}900.00 \\
0\end{array}$ & 0 & 900.000 \\
\hline 2 & 1 & 100.000 & 8 & $\begin{array}{r}800.00 \\
0\end{array}$ & 0 & 800.000 \\
\hline 3 & 5 & 100.000 & 4 & $\begin{array}{r}2.000 .0 \\
00\end{array}$ & $\begin{array}{r}1.500 .0 \\
00\end{array}$ & 3.500 .000 \\
\hline 4 & 1 & 0 & 3 & - & $\begin{array}{r}1.100 .0 \\
00\end{array}$ & 1.100 .000 \\
\hline 5 & 1 & 100.000 & 7 & $\begin{array}{r}700.00 \\
0\end{array}$ & 0 & 700.000 \\
\hline 6 & 1 & 0 & 2 & - & $\begin{array}{r}500.00 \\
0 \\
\end{array}$ & 500.000 \\
\hline
\end{tabular}

Pada Tabel 6 mendeskripsikan biaya pengolahan lahan oleh petani responden. Jumlah tenaga kerja, hari orang kerja, dan sewa traktor yang di pakai oleh setiap petani responden berbeda-beda dimna responden no 1 yang memiliki luas lahan 2,00 (ha) menggunakan 3 orang tenaga kerja, membutuhkan waktu kerja selama 3 hari. 
Responden no 2 memiliki luas lahan 1,50 (ha) menggunakan 1 orang tenaga kerja, membutuhkan waktu kerja selama 8 hari, waktu kerja pada petani responden no 2 memiliki waktu kerja yang lebih lama dari responden yang lain karena hanya menggunakan 1 orang tenaga kerja sehingga waktu kerjanya tentu lebih lama di bandingkan responden no 1 yang menggunakan 3 orang tenaga kerja. Responden no 3 memiliki luas lahan 1,00 (ha) menggunakan 5 orang tenaga kerja, membutuhkan waktu kerja selama 4 hari, dan menggunakan jasa sewa traktor. Dapat dilihat pada responden no 3 yang penggunaan tenaga kerjanya lebih banyak dibandingkan responden no 1 yang lahannya lebih besar dari pada responden no 3 , hal tersebut disebabkan karena kurangnya cara memanajemen sehingga berpengaruh terhadap biaya pengeluaran petani. Responden no 4 memiliki luas lahan 0,12 (ha), menggunakan 1 orang tenaga kerja, membutuhkan waktu kerja selama 3 hari, dan menggunakan jasa sewa traktor. Responden no 5 memiliki luas lahan 0,06 (ha), menggunakan 1 orang tenaga kerja membutuhkan, membutuhkan waktu kerja selama 7 hari Responden no 6 memiliki luas lahan 0,04 (ha), menggunakan 1 orang tenaga kerja, membutuhkan waktu kerja selama 2 hari, dan menggunakan jasa sewa traktor.

\section{Pemupukan dan Pengendalian Hama}

Pemeliharaan tanaman dilakukan dengan tujuan untuk mempertahankan kondisi pertumbuhan tanaman yang subur atau tanaman tersebut selalu sehat. Dalam menghasilkan produksi semua petani menginginkan produksi kangkung yang akan dihasilkan meningkat dan memiliki kualitas kangkung yang baik untuk memiliki tingkat harga yang tinggi dipasaran, dengan itu para petani merawat tanaman kangkung dengan pemberian pupuk dan pestisida. Pada waktu pemupukan petani menggunakan satu macam pupuk yaitu pupuk urea, petani juga membutuhkan satu sampai dua sak pupuk urea dengan luas lahan satu hektar dengan pemberian pupuk sebanyak satu sampai dua kali pemupukan dalam seminggu sampai seterusnya pemberian pupuk selalu diatur.

\begin{tabular}{llrrr}
\multicolumn{7}{l}{ Tabel 7. Biaya Pemupukan } \\
\hline \multicolumn{5}{c}{ Biaya Pemakaian Pupuk } \\
\hline Responden & $\begin{array}{l}\text { Jenis } \\
\text { Pupuk }\end{array}$ & $\begin{array}{r}\text { Pemakaian } \\
\text { (Sak/Bulan) }\end{array}$ & $\begin{array}{c}\text { Harga/Sak } \\
\text { (Rp) }\end{array}$ & $\begin{array}{c}\text { Total Biaya } \\
\text { Pupuk (Rp) }\end{array}$ \\
\hline 1 & & 12 & 90.000 & 1.080 .000 \\
2 & Urea & 12 & 90.000 & 1.080 .000 \\
3 & Urea & 12 & 90.00 & 1.080 .000 \\
4 & Urea & 4 & 90.000 & 360.000 \\
5 & Urea & 4 & 90.000 & 360.000 \\
6 & Urea & 8 & 90.000 & 720.000 \\
\hline & Urea & 9 & 90.000 & 780.000 \\
\hline
\end{tabular}

Pada Tabel 7 mendeskripsikan pemakaian pupuk oleh petani responden. Jumlah pupuk yang digunakan tidak sama, hal ini disesuaikan dengan luas lahan dan kondisi lahan serta teknik pemberian yang diterapkan masing-masing petani responden. Seperti responden no 1,2,dan 3 memiliki jumlah pemakaian pupuk yang sama walaupun luas lahan yang di tanami ukurannya berbeda dan yang lebih menonjol dari 6 petani responden yang ada yaitu petani responden no 6 dimana luas lahan yang diusahakannya lebih kecil dari pada responden no 4 dan 5 . Hal tersebut disebabkan karena setiap petani memiliki teknik dan takaran pemberian pupuk yang berbeda. Pada waktu penyemprotan hama penyakit para petani menggunakan berbagai macam obat yang sesuai dengan hama yang menyerang adapun obat-obat pembasmi hama yang dipakai antara lain Desis, Kenon, Ekstratin, Coracron, Virtako, Metador, Regen, dan Baifolan. Waktu penyemprotan sebanyak satu sampai dua kali dalam seminggu dan sesuai dengan besarnya penyerangan sampai jumlah hama terkontrol. Tabel 8 menunjukan besarnya biaya yang dikeluarkan petani untuk pengendalian hama.

\begin{tabular}{|c|c|c|c|}
\hline \multicolumn{4}{|c|}{ Biaya Pemakaian Obat Pengendali Hama } \\
\hline Responden & Jumlah Jenis Obat & $\begin{array}{c}\text { Pemakaian } \\
\text { (Botol/Bulan) }\end{array}$ & $\begin{array}{l}\text { Total Biaya } \\
\text { Pupuk (Rp) }\end{array}$ \\
\hline 1 & 2 & 12 & $772.000,00$ \\
\hline 2 & 2 & 12 & $772.000,00$ \\
\hline 3 & 2 & 12 & $540.000,00$ \\
\hline 4 & 2 & 4 & $390.000,00$ \\
\hline 5 & 3 & 4 & $140.000,00$ \\
\hline 6 & 3 & 8 & $430.000,00$ \\
\hline & 2 & 6 & $507.333,00$ \\
\hline
\end{tabular}

Dari Tabel 8 dapat dilihat penggunaan obat pengendali hama sangat berbeda, disesuaikan dengan jenis hama yang menyerang dan persentase tanaman yang terserang atau besarnya penyerangan. Petani sudah mengetahui jenis hama dan teknik pengendalian setiap hama tersebut, selain jenis obat pengendali hama, petani juga 
mengetahui setiap merek dagang dari setiap obat pengendali hama kangkung.

\section{Total Biaya Usahatani Kangkung}

Dari Tabel 9 total biaya dalam usaha tani ini berbeda-beda karena lahan yang dikelola petani bervariasi luasnya dan juga setiap petani memiliki keahlian masing-masing, seperti biaya pengolahan tanah yang dikeluarkan oleh responden no 3 lebih tinggi di bandingkan responden no 1, meskipun luas lahan responden no 1 lebih luas. dari pada responden no 3 . Hal ini disebabkan karena responden no 3 menggunakan tenaga kerja lebih banyak dan menggunakan traktor pada waktu pengolahan lahan. Biaya bibit pada responden no 1 lebih tinggi dari pada responden yang lain, karena lahan responden no 1 lebih besar dari pada responden yang lain, dan responden lain memiliki biaya pembelian bibit yang berbeda, karena bibit sebagian petani responden sudah ada yang dalam arti bibit yang suda ada di lahan tersebut lalu di diambil untuk di jadikan bibit kangkung yang baru. Ada juga petani responden lain yang membeli bibit kangkung dari daerah lain, seperti bibit dari Tondano. Begitu juga dengan biaya pengendalian hama dan pemupukan, ada biayanya yang sama dan ada yang biayanya berbeda, hal tersebut dikarenakan setiap petani memiliki keahlian dan cara bertani yang berbeda.

\begin{tabular}{|c|c|c|c|c|c|c|}
\hline Responden & $\begin{array}{l}\text { Pengolahan } \\
\text { Lahan (Rp) }\end{array}$ & Bibit (Rp) & $\begin{array}{c}\text { Obat } \\
\text { Pengen } \\
\text {-dalian } \\
\text { Hama } \\
\text { (Rp) }\end{array}$ & $\begin{array}{c}\text { Pupuk } \\
\text { (Rp) }\end{array}$ & $\begin{array}{c}\text { Upah } \\
\text { Tenaga } \\
\text { Kerja } \\
(\text { Rp) }\end{array}$ & $\begin{array}{c}\text { Total } \\
\text { Biaya } \\
\text { (Rp) }\end{array}$ \\
\hline 1 & 900.000 & 1.000 .000 & 772.000 & $\begin{array}{r}1.080 .0 \\
00\end{array}$ & 20.000 & $\begin{array}{r}3.772 .0 \\
00\end{array}$ \\
\hline 2 & 800.000 & 500.000 & 772.000 & $\begin{array}{r}1.080 .0 \\
00\end{array}$ & 20.000 & $\begin{array}{r}3.172 .0 \\
00\end{array}$ \\
\hline 3 & 3.500 .000 & 900.000 & 540.000 & $\begin{array}{r}1.080 .0 \\
00\end{array}$ & 20.000 & $\begin{array}{r}6.040 .0 \\
00\end{array}$ \\
\hline 4 & 1.100 .000 & 300.000 & 390.000 & 360.000 & 20.000 & $\begin{array}{r}2.170 .0 \\
00\end{array}$ \\
\hline 5 & 700.000 & 300.000 & 140.000 & 360.000 & 20.000 & $\begin{array}{r}1.520 .0 \\
00\end{array}$ \\
\hline 6 & 500.000 & 150.000 & 430.000 & 720.000 & 20.000 & $\begin{array}{r}1.820 .0 \\
00\end{array}$ \\
\hline Rata-rata & 1.216 .667 & 525.000 & 507.333 & 780.000 & 20.000 & $\begin{array}{r}3.082 .3 \\
33\end{array}$ \\
\hline
\end{tabular}

\section{Total Penerimaan}

Pemanenan kangkung dilakukan setelah kangkung berumur 7 minggu, dan waktu panen ke 2 sampai masa panen berikutnya kangkung di panen setiap 2 minggu sampai dengan tanaman tersebut tidak lagi bertumbuh dengan baik. Kangkung dijual petani pada pedagang pengumpul dalam satu ikatan yang disebut (bal), dalam satu bal terdiri dari 50 ikatan kecil dimana setiap ikatan kecil terdiri dari 6 sampai dengan 10 batang kangkung sesuai diameter batang kangkung.

\begin{tabular}{lrrr}
\multicolumn{2}{c}{ Tabel 10. Total Produksi dan Total Penerimaan dam 1 bulan } \\
\hline Responden & $\begin{array}{c}\text { Jumlah produksi } \\
\text { (bal) }\end{array}$ & $\begin{array}{c}\text { Harga/bal } \\
\text { (Rp) }\end{array}$ & $\begin{array}{c}\text { Total } \\
\text { Penerimaan } \\
(\mathbf{R p})\end{array}$ \\
\hline 1 & 750 & $60.000,00$ & $45.000 .000,00$ \\
2 & 450 & $80.000,00$ & $36.000 .000,00$ \\
3 & 375 & $60.000,00$ & $22.500 .000,00$ \\
4 & 85 & $60.000,00$ & $5.100 .000,00$ \\
5 & 60 & $60.000,00$ & $3.600 .000,00$ \\
6 & 60 & $60.000,00$ & $3.600 .000,00$ \\
\hline Rata-rata & 296,6666667 & 63.333 & 19.300 .000 \\
\hline Sura
\end{tabular}

Sumber : Data Olahan

Dari Tabel 10 dapat dilihat jumlah produksi petani kangkung berbeda-beda dikarenakan luas lahan yang digunakan serta teknik pemeliharaannya, jumlah produksi ini merupakan jumlah produksi selama 1 bulan. Responden no 1 memiliki jumlah produksi yang tertinggi dibandingkan dengan responden yang lain, yakni sebesar 750 bal karena responden no 1 memiliki lahan yang paling luas dibandingkan dengan responden lain yakni seluas 2,00 ha, dan status kepemilikan lahan milik sendiri. Responden no 2 memiliki jumlah produki 450 bal dengan luas lahan yang diusahakan 1,5 ha, sedangkan responden no 3 memiliki jumlah produksi 375 bal dengan luas lahan yang diusahakan 1,00 ha, responden no 4 jumlah produksinya 85 bal dengan luas lahan yang diusahakan 0,06 ha, dan responden no 5 memiliki jumlah produksi 60 bal dengan luas lahan yang paling sempit (0.04 ha) tetapi jumlah produksinya sama dengan responden no 6 yaitu 60 bal dalam 1 bulan.

Harga jual merupakan salah satu variabel penting yang menentukan besarnya penerimaan dari usaha tani kangkung, harga jual ditentukan oleh pembeli. Harga jual juga tergantung pada ketersediaan kangkung di pasar, makin banyak kangkung yang ada di pasar makin rendah harga jualnya, dan sebaliknya makin sedikit kangkung yang tersedia di pasar maka harganya semakin tinggi. Selain ketersediaan kangkung di pasar, harga jual juga ditentukan oleh tempat penjualan. Harga di pasar lebih tinggi dibanding 
dengan harga di kebun. Dari ke 6 responden hanya responden nomor 2 yang langsung menjual kangkung ke Pasar Girian, dan mendapat nilai jual tertinggi yakni $\mathrm{Rp}$ $80.000,00$ per bal sementara 5 responden lainnya menjual langsung di tempat (di kebun) kepada pedagang pengumpul dengan harga Rp60.000,00 per bal. Penerimaan merupakan perkalian antara total produksi (dalam bal) dan harga kangkung per bal seperti pada Tabel 15 . Penerimaan setiap responden sesuai dengan jumlah produksinya dan hara jualnya. Responden 1 total penerimaan lebih tinggi dibandingkan dengan 5 responden lainnya yakni $\mathrm{Rp}$. 45.000.000,00 diikuti dengan responden 2 Rp.36.000.000,00, responden 3 Rp 22.500.000,00 dan responden 4 Rp. 5.100.000,00, dan responden 5 dan 6 Rp.3.600.000,00.

\section{Pendapatan Usahatani Kangkung}

Pendapatan usahatani merupakan selisih antara total penerimaan dengan total biaya.

\begin{tabular}{lccr}
\multicolumn{2}{c}{ Tabel 11. Pendapatan Usahatani Kangkung } & \\
\hline Responden & $\begin{array}{c}\text { Total } \\
\text { Penerimaan } \\
(\mathbf{R p})\end{array}$ & $\begin{array}{c}\text { Total Biaya } \\
(\mathbf{R p})\end{array}$ & $\begin{array}{c}\text { Total } \\
\text { Pendapatan } \\
(\mathbf{R p})\end{array}$ \\
\hline 1 & $45.000 .000,00$ & 3.772 .000 & 41.228 .000 \\
2 & $36.000 .000,00$ & 3.172 .000 & 32.828 .000 \\
3 & $22.500 .000,00$ & 6.040 .000 & 16.460 .000 \\
4 & $5.100 .000,00$ & 2.170 .000 & 2.930 .000 \\
5 & $3.600 .000,00$ & 1.520 .000 & 2.080 .000 \\
6 & $3.600 .000,00$ & 1.820 .000 & 1.780 .000 \\
\hline Rata-rata responden & $24.532 .859,00$ & 3.082 .333 & 16.217 .667 \\
\hline Rata- rata per ha & $24.532 .859,00$ & 3.918 .054 & 20.614 .804 \\
\hline
\end{tabular}

Dari Tabel 11 dapat di lihat total pendapatan responden no 1 memiliki pendapatan yang paling tinggi dari antara responden lainnya yaitu $\mathrm{Rp}$. 41.228.000, karena luas lahan dan produksinya lebih besar dari pada 5 responden yang lain. Responden no 2 memiliki jumlah pendapatan yaitu Rp. 32.828.000 yang hampir mendekati pendpatan responden no 1 . Responden no 3 memiliki jumlah pendapatan yaitu Rp. 16.460.000, pendapatan tersebut menurun jauh dari responden no 1 dan 2 karena lahan dan produksinya lebih kecil sedangkan yang lebih berpengaruh ialah biaya pengolahan dari responden no 3 lebih besar di bandingkan responden yang lain sehingga pendapatan responden no 3 lebih kecil dari pada nilai yang diharapkan. Responden no 4 memiliki jumlah pendapatan yaitu Rp. 2.930 .000 karena lahan yang di gunakan dan nilai produksinya lebih kecil.
Responden no 5 memiliki jumlah pendapatan yaitu Rp. 2.080.000. Responden no 6 memiliki jumlah pendapatan yaitu Rp. 1.780.000, pendapatan dari responden no 6 lebih kecil di bandingkan resonden no 5 karena luas lahannya lebih sempit dan biaya pengolahannya lebih besar dari pada responden no 5 sehingga berpengaruh terhadap pendapatannya yang lebih rendah. Ratarata penerimaan dalam satu bulan per responden Rp. 19.300.000,00; rata-rata biaya per responden Rp. 3.082.333,00 dan pendapatan rata-rata per petani Rp.16.217.667,00. Sedangkan rata-rata penerimaan dalam satu bulan per hektar Rp. 24.532.859,00; rata-rata biaya per hektar $\mathrm{Rp}$. 3.918.054,00 dan pendapatan rata-rata per hektar Rp. $20.614 .804,00$

\section{KESIMPULAN DAN SARAN}

\section{Kesimpulan}

Pendapatan rata-rata usahatani kangkung di Desa Kaima per bulan per hektar sebesar Rp.20.614.804,00 dan pendapatan rata-rata per petani responden sebesar Rp.16.217.667,00.

\section{Saran}

1. Petani kangkung di Desa Kaima sebaiknya memasarkan hasilnya langsung ke pedagang yang ada di pasar, agar memperoleh harga jual yang lebih tinggi dibandingkan dengan menjual pada pedagang pengumpul yang datang ke desa.

2. Perlu informasi dan bimbingan teknis dari instansi terkait agar usahatani kangkung ini dapat lebih diminati petani.

\section{DAFTAR PUSTAKA}

Ahmad Tusi (2014). Mekanisasi Pertanian Penanaman. Jurusan Teknik Pertanian UNILA. Staff. unila. ac.id/ atusi/ files/ 2014/09/Handout-Mekanisasi-pertanianPenenaman.pdf.

Anonim, (2003). Dasar-Dasar Manajemen .(Bahan Kuliah) Universitas Sam Ratulangi Fakultas Pertanian Jurusan Sosial Ekonomi.

Danang Sunyoto, (2015). Studi Kelayakan Bisnis. CAPS (Center Of Academic Publishing Service). 
Darsono Prawironegoro, Purwanti, Ari. 2009. Akuntansi Manajemen. Jilid 1. Edisi ke empat. Erlangga, Jakarta

Eprints.undip.ac.id (2011). Jurnal Analisis Penyerapan Tenaga Kerja di Salatiga.

Ferra Pujianti Spd,(2015). Rahasia Cepat Menguasai Laporan Keuangan Dengan Akuntansi Dasar. Penerbit Lembar Pustaka Indonesia.

Fredi Kurniawan (2016). http:// fredikurniawan.com/ klasifikasi-dan-morfolgi-tanaman-kangkung/

Hansen dan Mowen (2004) http:// herryakmen.blogspot.co.id/2011/09/konsepbiaya.html di akses pada tanggal 25/7/15

Hernanto dan Zulkifli (2003) http:// herryakmen.blogspot.co.id/2011/09/konse p-biaya.html di akses pada tanggal 25/7/15

H. Malayu S.P. Hasibuan (2016). Manajemen Dasar, Pengertian, dan Masalah. Edisi Revisi. PT.Bumi Aksara. Jakarta.

http://www.materipertanian.com/klasifikasi-dan-ciriciri-morfologi-kangkung/ diakses tanggal 18/04-16

Huriyah Badriah, (2014). Buku Pintar Akuntansi Dagang Untuk Orang Awam. Penerbit Yudhistira Jakarta.

Informasi Ilmu Pertanian Indonesia (2017). Pengertian dan Definisi Pasca Panen. Agroteknologi.Web.id.

Kangkung PDF (2016) (Kangkung.pdf - Fixit Reader )

Ken Suratiyah (2008) Tinjau Pustaka Konsep Usaha Tani. UNILA. Digilid.unila.ac.id. bab 2.pdf. Di akses 14-jul-2017 Jam 06:30 WITA

Ken Suratiyah. 2009. Ilmu Usahatani. PT. Penebar Swadaya. Jakarta.

Kotler, Philip dan Gary Amstrong (2001). PrinsipPrinsip Pemasara. Jilid 1 Edisi Kedelapan. Jakarta

Kotler, Phillip, (2005). Manajemen Pemasaran Jilid 1 dan 2. PT. Indeks Kelompok Gramedia. Jakarta

Laksana, Fajar. (2008). Manajemen Pemasaran. Yogyakarta: Penerbit Dharma Ilmu.

Luntungan, (2012). Analisis Tingkat Pendapatan Usaha Tani Tomat Apel di Kecamatan Tompaso Kabupaten Minahasa. Jurnal Pembangunan Ekonomi dan Keuangan Daerah (PEKD) Universitas Sam Ratulangi. Manado

Mulyadi Subri. (2003). Ekonomi Sumber Daya Manusia. PT Raja Grafindo Persada Jakarta.
Paristiyanti Nurwardani (2008). Teknik Pembibitan Tanaman dan produksi benih. Jilid 1. Untuk Sekolah Menengah Kejuruan. Penerbit Direktorat Pembinaan SMK. Departemen Pendidikan Nasional.

Pelatihan penanaman Hutan di Maluku UtaraAmbon (2007). indonesiaforest. webs.com/tanam_lady.pdf.

Raden Fatah (2014). Landasan TeoriPendapatan $P D F$. Eprints.Radenfatah.ac.id.

Rano K. Limbong (2011). Manajemen Pemupukan Kelapa Sawit Di Gunung Sari Estate, PT.Ladangrumpun Suburabadi, Minamas Plantation, Kab. Tanah Bumbu, Kalimantan Selatan. Manajemen Pemupukan Kelapa Sawit PDF, repository.ipb.ac.id. 19-06-2017 06:30 WITA

Rodjak, A. (2006). Manajemen Usahatani. Bandung: Pustaka Gitaguna.

Sadono Sukirno, et al. (2004). PENGANTAR BISNIS. Edisi Pertama. KENCANA PRENADAMEDIA GROUP. Rawamangun Jakarta.

Saril Gunawan (2014). Unsur-Unsur Pokok Usahatani. http://plus.google.com/

Shinta.A. (2011). Ilmu Usahatani. Universitas Brawijaya Press. Malang.

Soekartawi. (1996). Pembangunan Pertanian Untuk Menentaskan Kemiskinan. Universitas Indonesia. Jakarta.

Suhendi dan Indra Sasangka, (2014). PENGERTIAN BISNIS. ALFABETA, CV. BANDUNG

Sukirno. (2000). Mikro Ekonomi Moderen.Perkembangan Pemikiran dari Klasik Sampai Keynesian Baru, Edisi 1. PT Raja Grafindo. Jakarta.

Sutedjo,M. (2010). Pupuk dan Cara Pemupukan. Rineka Cipta.Jakarta.

Tim Ahli Guru, 2006. IPS Terpadu SMP kls 1 Jilid 1A.

Usman (2006). Manajemen Pemasaran. Cetakan pertama. Yogyakarta. Penerbit Amara Books.

V. Wiratna Sujarweni (2015). AKUNTANSI BIAYA. Teori dan Penerapannya. Penerbit Pustaka Baru Press Yogyakarta.

William G. Nickels, James M. Mchugh, Susan M. McHugh, (2009). Pengantar Bisnis.(Understending Business) Edisi 8 Penerbit Salemba Empat.

Wilson Bangun. (2007). Teori Ekonomi Mikro. PT. Refika Aditama. 